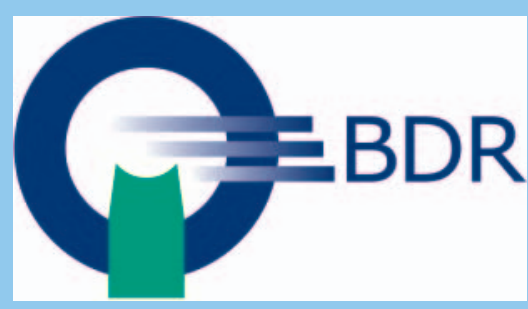

\title{
Best New Radiology Software: BerlinCaseViewer belegt den 2. Platz bei den 2021 EuroMinnies Awards
}

Am 25. Februar prämierte AuntMinnieEurope.com die besten radiologischen Errungenschaften des Jahres 2020. Hierfür konnten die über 31000 Mitglieder der radiologischen Plattform ihre Vorschläge in 8 Kategorien von „Most Influential Radiology Researcher“ bis hin zu „Best New Radiology Vendor" einreichen. Ein Gremium entschied darüber, wer ins Finale kommt. Zum Ende des Jahres 2020 dann die News: Unsere Radiologie-App, der BerlinCaseViewer, hatte es mit dem kostenlosen Modul zur COVID-19-Pneumonie in der Kategorie „Best New Radiology Software“ zuerst auf die Shortlist und schließlich ins Finale geschafft.

\section{Der BCV im Wettbewerb mit 14 weiteren Nominierten}

Insgesamt gelangten 15 Projekte in die engere Auswahl für die beste RadiologieSoftware. Mit dabei waren namhafte Unternehmen wie Siemens Healthineers, Agfa, Fujifilm, Hologic und TeraRecon - und unsereins aus Berlin. Eine Fachjury nahm alle Kandidaten genau unter die Lupe und entschied darüber, welche 2 Projekte ins Finale einziehen würden.

In der letzten Runde standen sich schließlich der Advanced Visualization Workspace - IntelliSpace Portal 12 von Philips Healthcare und das COVID-19-Quiz-Modul vom BerlinCaseViewer gegenüber.

Die Trophäe nahm am Ende das niederländische Unternehmen mit nach Hause. Aber für unser Team ist es auch ein Gewinn, auf dem Podium zu stehen.

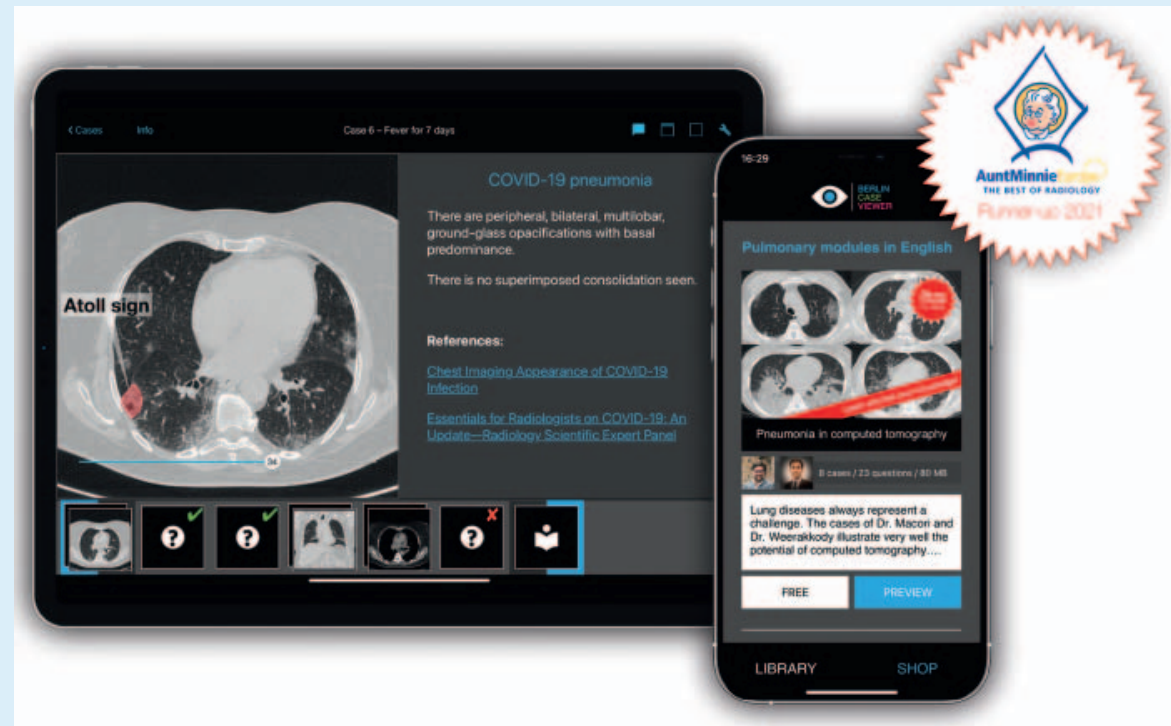

Zum Projekt: Wie die BerlinCaseViewer-App hilft, COVID-19 zu diagnostizieren und zu behandeln

Früh war klar: Mit der interaktiven Bildgebungs-App BerlinCaseViewer wollten wir das neuartige Coronavirus in den Fokus nehmen, um einen Beitrag zu leisten. Denn eine der Herausforderungen, vor die uns die Pandemie gestellt hat und noch immer stellt, ist, die COVID-19-Pneumonie von anderen Lungenerkrankungen zu unterscheiden.

Zusätzlich zum PCR-Test empfiehlt die Fleischner-Gesellschaft daher den Einsatz der CT-Bildgebung, insbesondere wenn sich der Zustand von Patientinnen/Patienten verschlechtert. Anhand bestimmter Muster lässt sich COVID-19 in der CT von anderen entzündlichen und nichtentzündlichen Lungenerkrankungen abgrenzen. Vorausgesetzt, man erkennt die spezifischen Phänomene.

Für eine internationale Kooperation hat sich unser Team entsprechende Experten mit ins Boot geholt: Der Thoraxradiologe Dr. Fabio Macori hat die italienische Bevölkerung mit zeitgerechter und exakter Diagnostik versorgt und relevante Bilddatensätze für die BCV-Fallsammlung zur Verfügung gestellt. Der australische Radiologe Dr. Yuranga Weerakkody mit thorakaler Subspezialisierung und einer Begeisterung für elektronische Lehrmethoden hat sein Know-how beigesteuert. Gemeinsam haben wir ein interaktives Quiz-Format mit 19 Fällen inklusive Differenzialdiagnosen für die App entwickelt. 
Damit können Ärzte und Ärztinnen auf der ganzen Welt kostenlos ihren Blick für die relevanten radiologischen Anzeichen von COVID-19 schärfen. Die BerlinCaseViewerApp für das iPhone, iPad und den Mac steht zum Gratis-Download im App-Store und
Mac-App-Store bereit. Eine Version für Android-Geräte ist in Vorbereitung.

Informationen zum Projekt:

www.berlincaseviewer.de

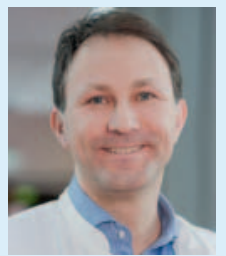

Prof. Dr. Kay-Geert Hermann, Berlin 